\title{
STUDY ON THE PRECISION OF 1-MINUTE X-BAND MP RADAR RAINFALL DATA IN A SMALL URBAN WATERSHED
}

\author{
YOSHITOMO YONESE ${ }^{1}$, AKIRA KAWAMURA $^{2}$, HIDEO AMAGUCHI $^{2}, \&$ AKIHIRO TONOTSUKA ${ }^{2}$ \\ ${ }^{1}$ CTI Engineering Co., Ltd., Japan. \\ ${ }^{2}$ Faculty of Urban Environmental Sciences, Tokyo Metropolitan University, Japan.
}

\begin{abstract}
In Tokyo metropolitan area, the flood risk is increasing due to social and environmental conditions including concentration of population and industry etc. In small urban watersheds, there exists a high risk of inundation by river flooding and/or inner water induced by heavy rainfall in a short time. To estimate river water level accurately in urban small rivers, it is critically important to obtain accurate rainfall data with high resolution of spatio-temporal distribution. X-band MP radar (X-band multiparameter radar), providing high resolution of spatio-temporal distribution rainfall data, is expected to be made effective use of its advanced detailed data. However, few studies on the precision evaluation of 1-minute X-band MP radar data were performed. In this study, a precision evaluation of X-band MP radar data was conducted by comparing radar data to 1-minute ground observation data, which is densely deployed in Tokyo Metropolitan area, provided by Tokyo Integrated Information System on Water Disaster Management. In this study, 10 heavy rainfall events in 2013 were selected as target events in the upper Kanda River, one of the typical urban small rivers in Tokyo. As for rainfall intensity, 1-minute data of X-band MP radar expressed a better peak accuracy compared with 10-minute data. The peak values of 10-minute data were underestimated about $30 \%$ in some event. One-minute data of X-band MP radar were observed a few minutes earlier than ground observation data. The falling time of rain drops is considered as the major factor of the difference. This study showed that it is possible to obtain detailed rainfall characteristics such as precise rainfall intensity and its time of occurrence by utilizing 1 -minute $\mathrm{X}$-band MP radar rainfall, which are not sufficiently provided by 10 -minute data and its extended resolution is anticipated to be practically useful in smaller urban watersheds.

Keywords: 1-minute data, ground observation rainfall data, Kanda Riverm, small urban watershed, $X$-band MP radar, XRAIN.
\end{abstract}

\section{INTRODUCTION}

Flood damage is frequently occurring in recent years due to localized concentrated heavy rainfall known as guerrilla-type rainstorms, which will be a threat to sustainable development of the city. Especially, in Tokyo metropolitan area, the flood risk is increasing due to social and environmental conditions including concentration of population and industry, as well as increase of flooding runoff due to urbanization and climate change. In small urban watersheds, there exists a high risk of inundation by river flooding or inner water induced by heavy rainfall in a short period. Thus, detailed runoff analysis has been conducted with 1-minute rainfall or water level observation data $[1,2]$. To precisely estimate river water level by such detailed runoff analysis, it is critically important to obtain detailed rainfall data and its spatial and temporal distribution with required preciseness.

X-band MP radar network (XRAIN), deployed by the Ministry of Land, Infrastructure, Transportation, and Tourism (MLIT) of Japan, started its full operation in March 2014 after the trial operation since 2010. The system provides detailed spatial and temporal distribution of rainfall data. The accuracy of X-band MP radar rainfall has been improved through recent studies on the characteristics of observation and precise estimation method of radar rainfall [3-5]. Existing studies utilizing the X-band MP radar rainfall with high resolution include: 


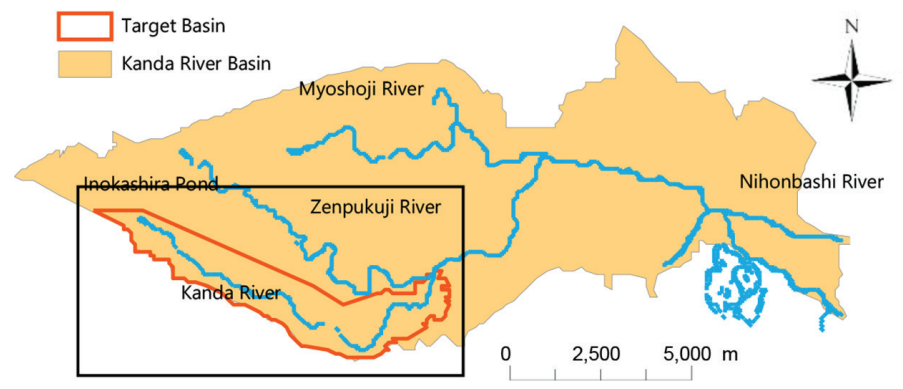

Figure 1: Target basin of the upper Kanda River.

the verification of the preciseness of rainfall or snowfall estimation by ground observation rainfall data [6], comparison of radar data and ground observation rainfall through range analysis in Nagoya region [7], and verification of estimated rainfall volume and spatial accuracy for rainfall events of low temporal resolution [8]. Taking advantage of the characteristics of radar rainfall observation, most of these studies focus on relatively large area of more than $30-40 \mathrm{~km}^{2}$. Among the researches on smaller basins [9], there exists a study on precision evaluation in a second-class basin $\left(21 \mathrm{~km}^{2}\right)$. The study points out that the gap in basin averaged rainfall between ground observation and X-band MP radar become larger in localized heavy rain which characterizes in relatively large spatial variance.

In the above described precision verification studies on X-band MP radar rainfall, 10-minute data is prepared from 1-minute rainfall and utilized considering the consistency to the observational time steps of ground observation. In the case of local area such as small urban watershed, since preciseness of rainfall in smaller time steps is critical, precision evaluation of 1-minute data itself is important. However, there is no such existing research.

In this study, 10 heavy rainfall events in 2013 were selected as the target events in upper Kanda River, one of the representing urban small rivers in Tokyo. A precision evaluation of $\mathrm{X}$-band MP radar data was conducted by comparing radar data to the ground observation data provided by Tokyo Integrated Information System on Water Disaster Management, which is densely deployed in Tokyo Metropolitan area.

\section{TARGET BASIN AND RAINFALL}

The Kanda River, the target basin, is originated in Inokashira Pond in Mitaka City, Tokyo. It flows into Shinjuku Ward after merging with the Zenpukuji River near the border of Nakano Ward. With the basin area of $105.0 \mathrm{~km}^{2}$ and the length of $25.48 \mathrm{~km}$, it is one of the largest among the small rivers in Tokyo and is designated as the first-class river [10]. In this study, $11.5 \mathrm{~km}^{2}$ of the upper Kanda River with the flowing distance of $9 \mathrm{~km}$ from Inokashira Pond to the merging point to the Zenpukuji River shown in Figure 1, was selected as the target area.

As for ground observation data, ground rain-gauge data by Tokyo Integrated Information System on Water Disaster Management was utilized. Ground observation sites around the target area are shown in Figure 2. Being divided by Thiessen polygons, the dominant area of each observation site is approximately $1.3 \mathrm{~km}^{2}$ in average. Observation sites are densely placed that the maximum dominant area is less than $3 \mathrm{~km}^{2}$. Rainfall is gauged every 1 minute at each site in the minimum unit of $1 \mathrm{~mm}$.

Target rainfall events were selected among the ones in 2013. Events that have brought a heavy rain to the target basin were extracted as the target. In small watersheds, heavy rainfall 


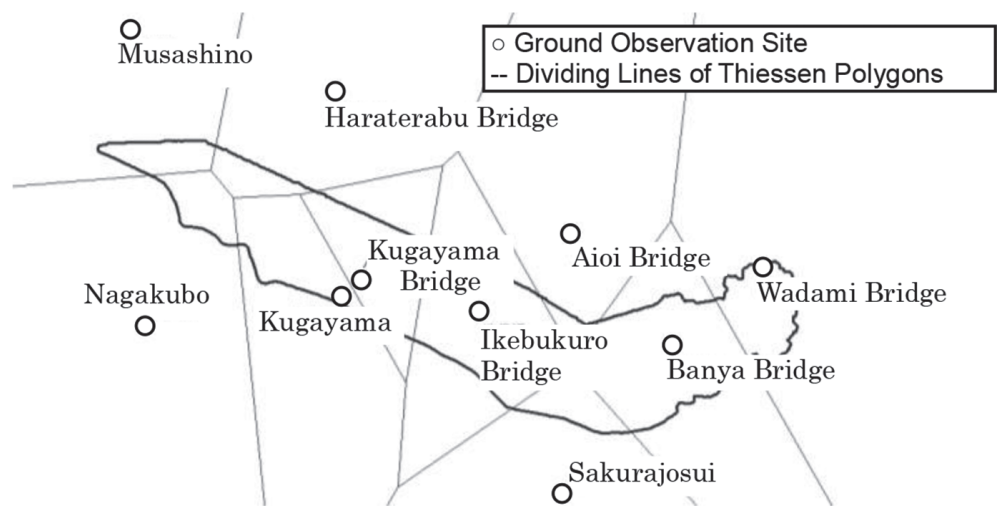

Figure 2: Ground observation sites and dividing lines of Thiessen polygons in the target basin.

in a short time can raise the river water level quickly, as the Toga River in 2008 where a heavy rainfall occurred around the basin in 30 minutes from 14:30 to 15:00 of July 28 and caused $1.34 \mathrm{~m}$ rise in the river water level only within 10 minutes. Thus, in selecting the validation target events, 10 events shown in Table 1 with over $10 \mathrm{~mm}$ rainfall intensity in 30 minutes at Kugayama bridge site were selected. The summary of target events, total rainfall volume, validation rainfall period, and rainfall cause of target events, are shown in Table 1.

Table 1: Target rainfall events.

\begin{tabular}{|c|r|r|r|r|r|l|}
\hline \multirow{2}{*}{$\begin{array}{c}\text { Rainfall } \\
\text { Event } \\
\text { No. }\end{array}$} & $\begin{array}{c}\text { 30-min. Cumulative Rainfall } \\
\text { (Kugayama Bridge) }\end{array}$ & \multicolumn{2}{|c|}{$\begin{array}{r}\text { rainfall duration and basin averaged total } \\
\text { rainfall }\end{array}$} & \\
\cline { 2 - 6 } & $\begin{array}{c}\text { Start of 30-min. } \\
\text { Period }\end{array}$ & $\begin{array}{c}\text { Volume } \\
(\mathrm{mm})\end{array}$ & Start of Event & $\begin{array}{c}\text { Rainfall } \\
\text { Duration } \\
\text { (hr:min) }\end{array}$ & $\begin{array}{c}\text { Total } \\
\text { Volume } \\
\text { (mm) }\end{array}$ & Cause of Rainfall \\
\hline 1 & $2013 / 09 / 0507: 44$ & 32 & $2013 / 09 / 0421: 11$ & $13: 46$ & 66.3 & low pressure \\
\hline 2 & $2013 / 06 / 2512: 22$ & 32 & $2013 / 06 / 2507: 33$ & $7: 07$ & 39.7 & $\begin{array}{l}\text { atmospheric } \\
\text { instability }\end{array}$ \\
\hline 3 & $2013 / 08 / 1217: 53$ & 31 & $2013 / 08 / 1217: 44$ & $12: 54$ & 44.3 & $\begin{array}{l}\text { atmospheric } \\
\text { instability }\end{array}$ \\
\hline 4 & $2013 / 09 / 1506: 49$ & 30 & $2013 / 09 / 1503: 50$ & $17: 31$ & 135.2 & typhoon No.18 \\
\hline 5 & $2013 / 07 / 2315: 45$ & 25 & $2013 / 07 / 2315: 36$ & $2: 55$ & 21.2 & $\begin{array}{l}\text { atmospheric } \\
\text { instability }\end{array}$ \\
\hline 6 & $2013 / 10 / 1603: 42$ & 19 & $2013 / 10 / 1511: 48$ & $19: 40$ & 195.6 & $\begin{array}{l}\text { typhoon and } \\
\text { stationary front }\end{array}$ \\
\hline 7 & $2013 / 08 / 2115: 55$ & 16 & $2013 / 08 / 2115: 36$ & $6: 40$ & 17.9 & front \\
\hline 8 & $2013 / 04 / 0622: 41$ & 16 & $2013 / 04 / 0615: 18$ & $11: 36$ & 88.7 & low pressure \\
\hline 9 & $2013 / 08 / 2623: 48$ & 12 & $2013 / 08 / 2622: 33$ & $9: 40$ & 45.1 & front \\
\hline 10 & $2013 / 08 / 1115: 16$ & 11 & $2013 / 08 / 1115: 01$ & $0: 46$ & 8.0 & $\begin{array}{l}\text { atmospheric } \\
\text { instability }\end{array}$ \\
\hline
\end{tabular}

\section{CHARACTERISTICS OF RAINFALL DATA OF GROUND OBSERVATION AND X-BAND MP RADAR}

To evaluate the precision of X-band MP radar rainfall in the target area, ground observed data at five sites (Kugayama, Kugayama Bridge, Ikebukuro Bridge, Banya Bridge, and Wadami 
Bridge) was compared to the X-band MP radar rainfall at corresponding meshes. Figure 3 shows the comparison of hyetograph and total rainfall volume between ground observation and X-band MP radar rainfall observed at Kugayama Bridge, Ikebukuro Bridge, and Banya Bridge for the rainfall event No.1. Since the minimum unit of the ground observation data is $1 \mathrm{~mm}$, the variance of ground observation, if described in $\mathrm{mm} / \mathrm{hr}$, is greater than that of $\mathrm{X}$-band MP radar as shown in Figure 3. According to the ground observation data, the event No.1 has the first peak during 5:00 to 6:00 and second one during 7:30 to 8:30. X-band MP radar shows rainfall peaks, both of the first and the second one, at almost the same or a little earlier than the ground observation. As for cumulative rainfall volume, although there exists around $20 \%$ gap at Kugayama Bridge, they reproduce almost the precise volume.

The precision of total rainfall volume is evaluated by the total rainfall ratio (total volume of X-band MP radar data divided by that of ground observation data), which has also been used in existing studies [3] as primary index. Around 10 to $20 \%$ gap in the total rainfall ratio is considered acceptable in existing studies.

Total rainfall ratios and correlation coefficients between X-band MP radar rainfall and ground observation rainfall are shown in Figures 4 (a) and (b), respectively. Looking closely the total rainfall ratio for each event, it is close to 1.0 for events No. 1, No.4, No.6, and No.8. They are all induced by typhoon or low pressure, which are characterized by long duration and large total volume of rainfall. Thus, it is considered that the preciseness of total rainfall ratio becomes higher under large total rainfall volume. As shown in the correlation coefficients for each event of Figure 4 (b), although there exists some variation between events or observation sites, correlation coefficients of rainfall events No.1 to No.5 are relatively high, where as they become lower for No.6 to No.10.

Figures 5 (a) and (b) show the total rainfall ratios and correlation coefficients between X-band MP radar rainfall and ground observation rainfall for each observation site. In the

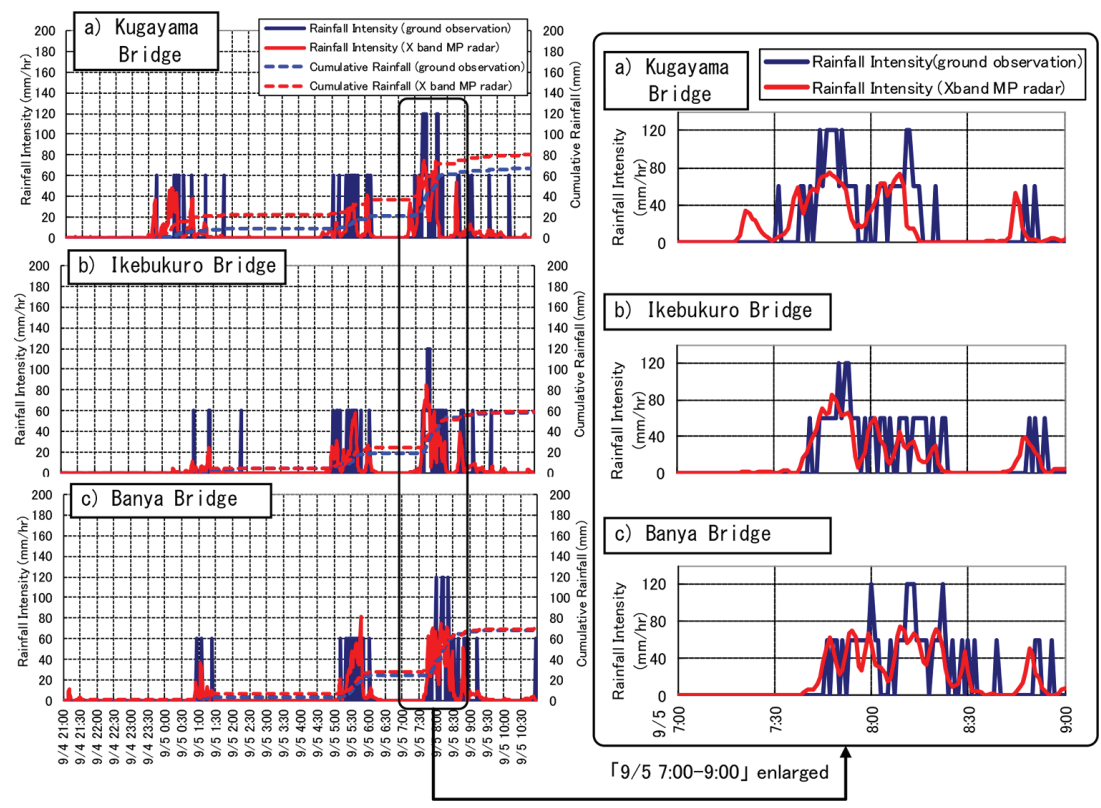

Figure 3: Comparison of hyetographs of ground observation and X-band MP radar. (rainfall event No.1). 

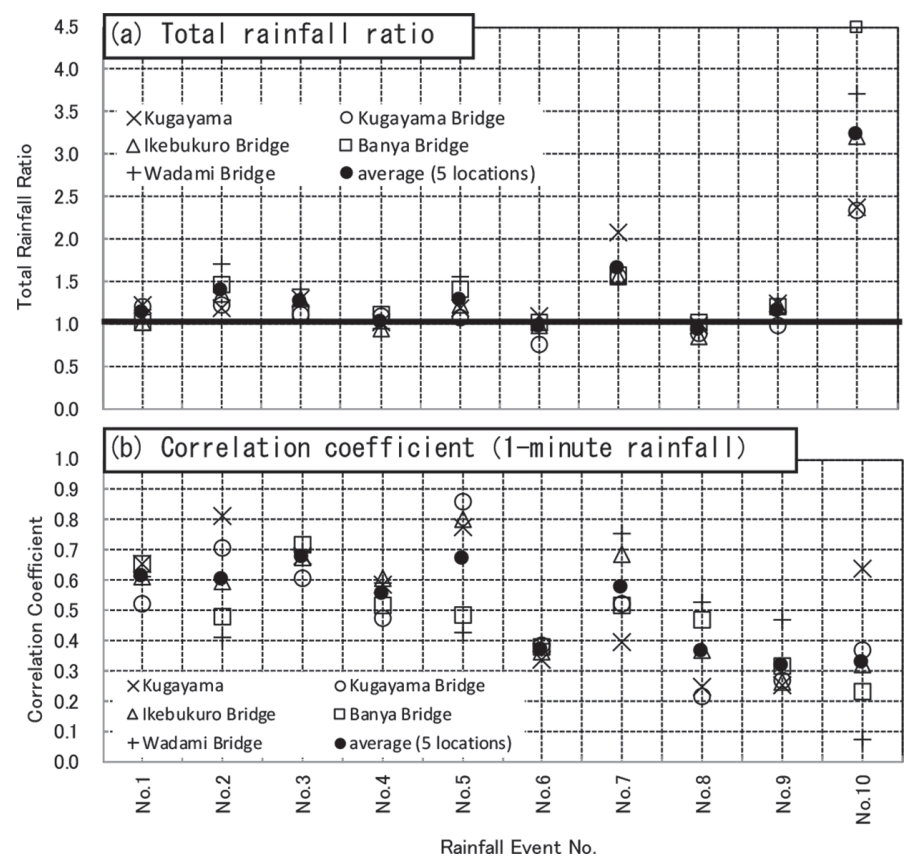

Figure 4: Comparison between ground observation and radar. (a) Total rainfall ratio (X-band MP radar rainfall divided by ground observation data); (b) Correlation coefficient.

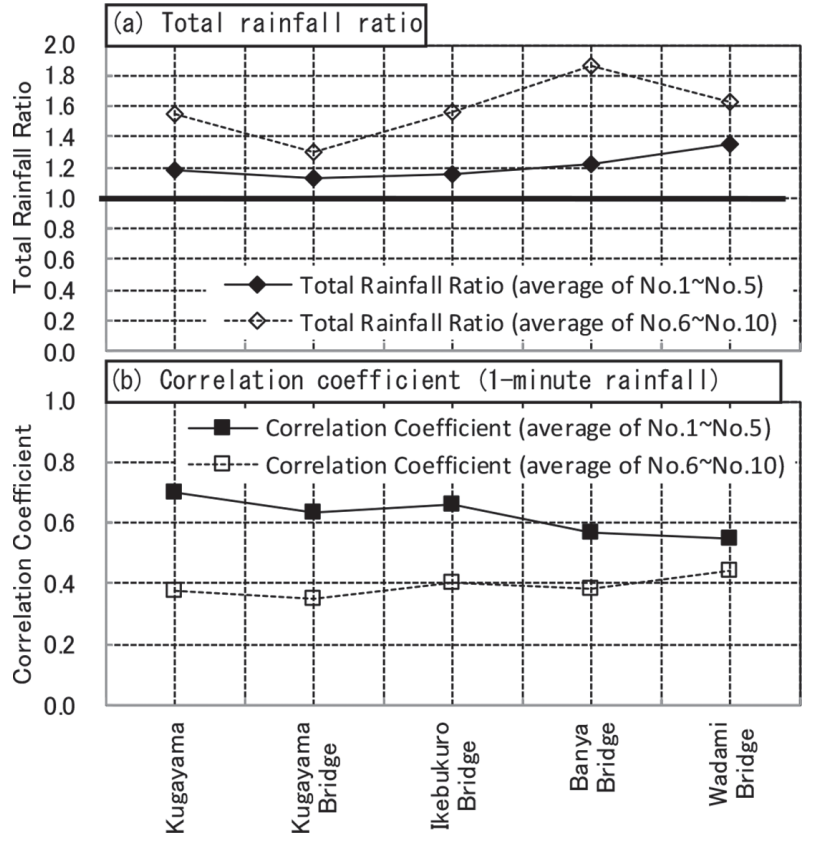

Figure 5: Comparison of the average of No.1-No.5 and No.6-No.10. (a) Total rainfall ratio; (b) Correlation coefficient (1-minute rainfall). 

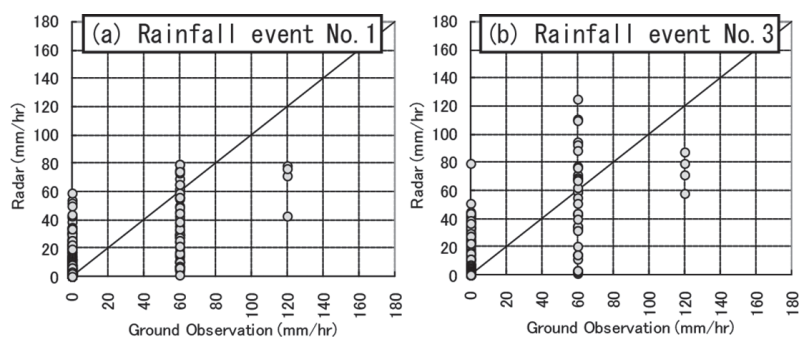

Figure 6: Scatter diagrams of 1-minute data of X-band MP radar and ground observation at Kugayama Bridge. (a) Rainfall event No.1; (b) Rainfall event No.3.

figures, black symbols show the average in the groups of rainfall events No.1 to No.5 with relatively large 30-minute rainfall volume, and white symbols show the average of No.6 to No.10 with relatively small volume. As shown in Figure 5 (a), the averaged total rainfall ratio of events No.1 to No.5 is approximately 1.21, while that of events No.6 to No.10 is approximately 1.59 . In cases with relatively large 30 -minute rainfall volume, the total rainfall ratio become closer to 1.0. As shown in Figure 5 (b), the averaged correlation coefficients for No.1 to No.5 are significantly higher than that for No.6 to No.10. Although X-band MP radar mostly capture the occurrence of rainfall observed by ground observation, the correlation coefficient remain small since the smoothness of rainfall variance cannot be captured by ground observation whose minimum unit is $1 \mathrm{~mm}$ (Fig. 6).

\section{PRECISION EVALUATION OF X-BAND MP RADAR RAINFALL USING BASIN AVERAGED RAINFALL}

\subsection{Precision evaluation by 1-minute data}

Precision evaluation of basin averaged rainfall was conducted by 1-minute data for the target basin. For ground observed rainfall, basin averaged data is calculated by Thiessen Method. For X-band MP radar rainfall, the basin averaged rainfall is defined as the average in the basin mesh area shown in Figure 7.

Figure 8 shows the total rainfall volume calculated from the basin averaged rainfall of $\mathrm{X}$-band MP radar and ground observation data. Cumulative rainfall in each mesh

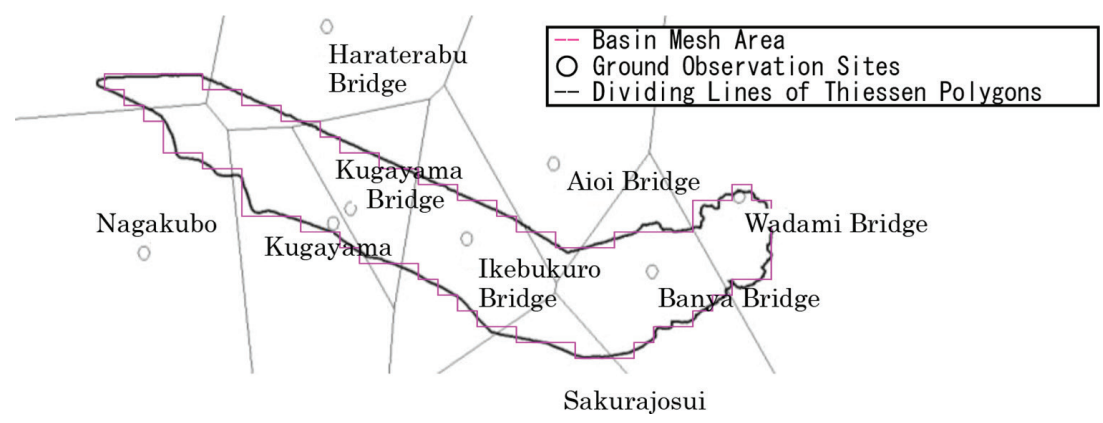

Figure 7: Mesh area of the target basin. 
calculated from X-band radar for the events No.1 to No.5 is shown in Figure 9. It is confirmed that rainfalls are not spatially uniform but there exists spatial distribution. As shown in Figure 9, rainfall No.1 and No.4 characterize in relatively high intensity in upper basin, while rainfall No.2 in relatively high intensity in the middle basin. As shown in Figure 8, the total rainfall volume of X-band MP radar and ground observation have variation in case of small rainfall, but are considered approximately consistent. It is considered that the total rainfall volume is adequately measured for various types of rainfall.

Hyetographs of basin averaged rainfall of ground observation and X-band MP radar is shown in Figure 10. Since the variance of basin averaged rainfall of ground observation is smaller compare to each ground observation data, hyetographs show a good correspondence between X-band MP radar and ground observation data.

Total rainfall ratios of basin averaged rainfall as well as the average of five sites for each event are shown in Figure 11 (a), and correlation coefficients are shown in Figure 11 (b). As described above for total rainfall ratio at each observation site, the total rainfall ratio of basin averaged rainfall become closer to 1.0 as total rainfall volume become large (such as events No.1, No.4, No.6, and No.8). Excluding the rainfall event No.10 whose total rainfall amount is relatively small shown in Table 1, the average total rainfall ratio for No.1 to No.9 is 1.15 , which is considered to have fair preciseness. From Figure 11 (b), correlation coefficient of

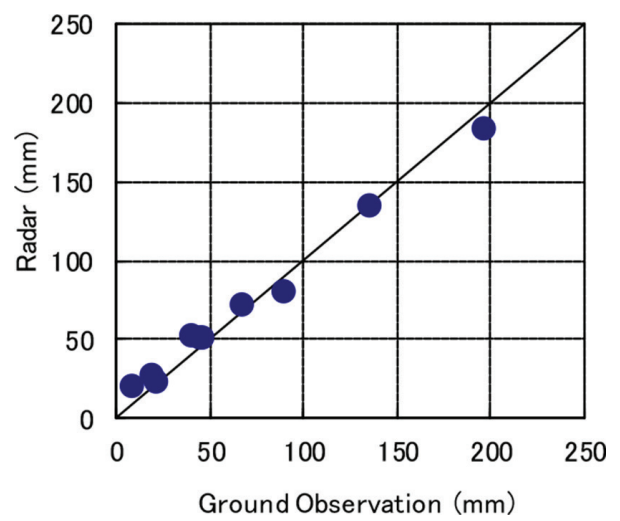

Figure 8: Basin averaged total rainfall volume of X-band MP radar and ground observation for each rainfall event.
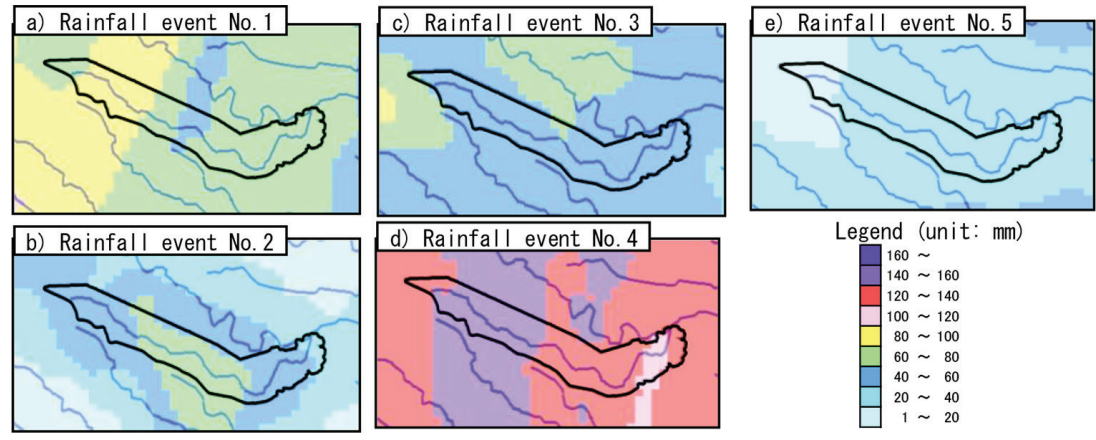

Figure 9: Cumulative rainfall in each mesh by X-band MP radar. 

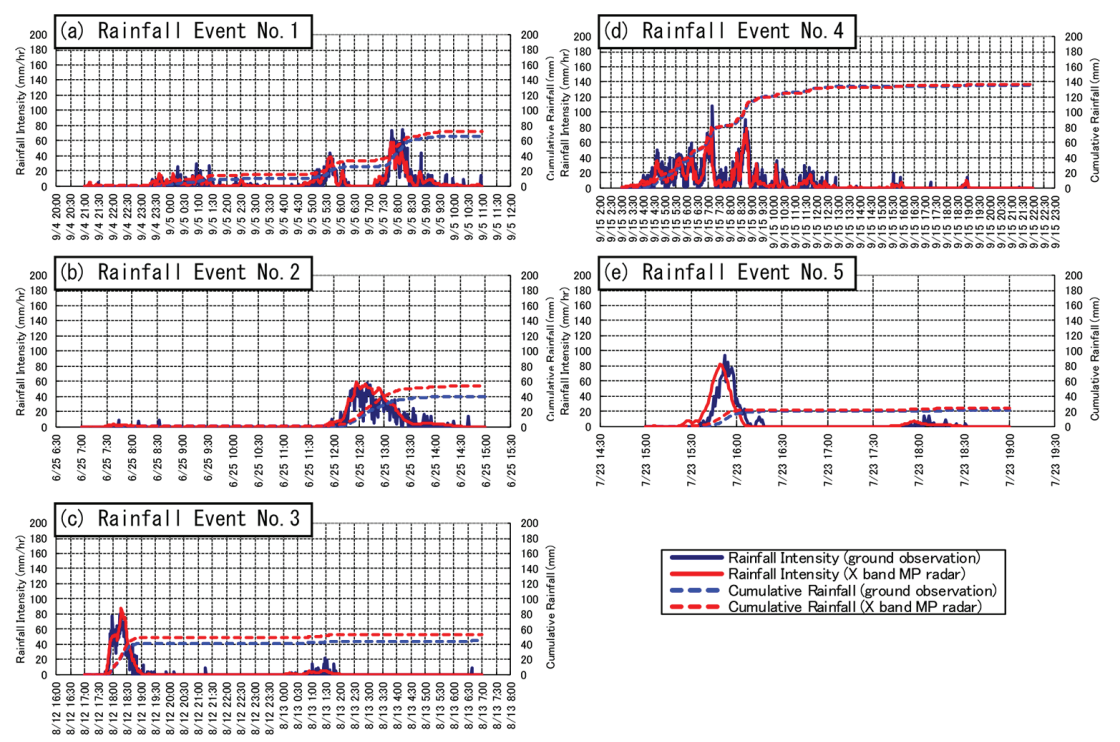

Figure 10: Comparison of ground rain-gauge and X-band MP radar (hyetographs of basin averaged 1-minute rainfall).
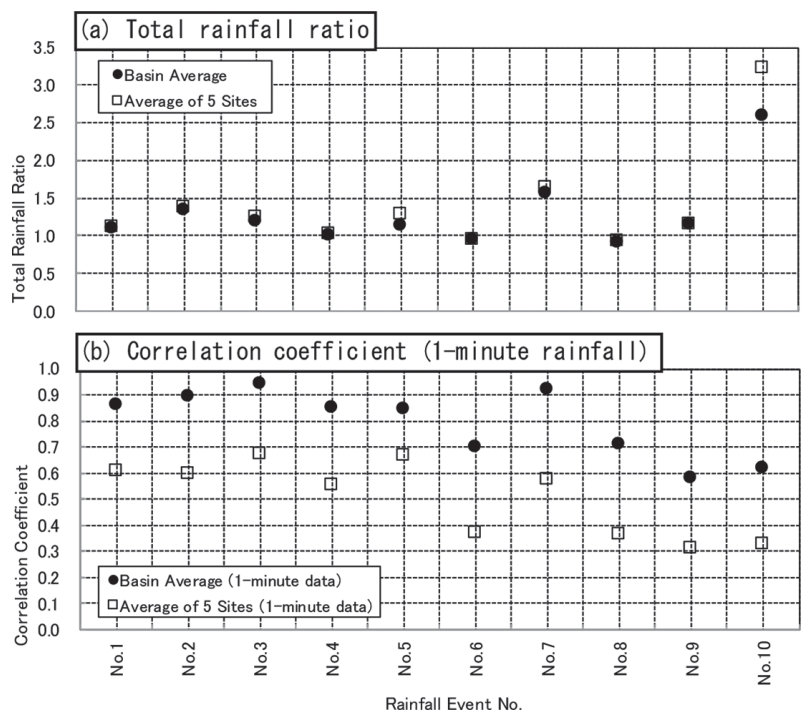

Figure 11: Comparison between basin average and the average of five sites. (a) Total rainfall ratio (X-band MP radar rainfall divided by ground observation data); (b) Correlation coefficient.

basin averaged 1-minute rainfall is 0.88 as average of rainfall events No.1 to No.5, and 0.71 as average of rainfall No.6 to No.10. These values are much larger compare to the average of five sites ( 0.62 as the average of No.1 to No.5). As shown in the scatter diagram of basin averaged 1-minute rainfall in Figure 12, this is mainly because ground observed hyetograph with minimum unit of $1 \mathrm{~mm}$ is smoothed by averaging discontinuous data shown in Figure 6 . 

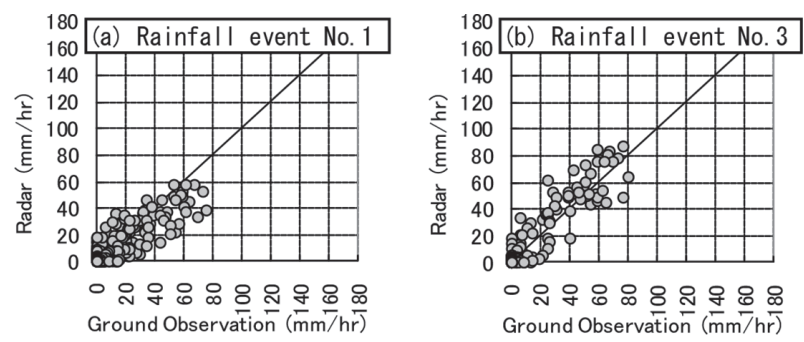

Figure 12: Scatter diagrams of basin averaged 1-minute rainfall between X-band MP radar and ground observation. (a) Rainfall event No.1; (b) Rainfall event No.3.

On the other hand, as shown in Figure 10 (e) on rainfall event No.5, X-band MP radar data is observed about 2-3 minutes earlier than ground observation, which results in the phase gap. As for other rainfalls, although the difference is not as clear as the event No.5, there exists about 1-2 minutes phase gap as well. The cause of this gap is considered due to the falling time of rain drops. For example, assuming the observation of rainfall at roughly $600 \mathrm{~m}$ in the sky, $50 \mathrm{~mm} / \mathrm{hr}$ of rainfall with around $2 \mathrm{~mm}$ diameter of raindrop, and $6.6 \mathrm{~m} / \mathrm{s}$ of falling velocity, the falling time to the ground will be approximately 2 minutes.

\subsection{Precision evaluation by 10 -minute data}

Since existing studies on rainfall evaluation is conducted mostly by 10 -minute rainfall in consistent to observing time steps of the ground observation, an evaluation of 10-minute rainfall of ground observation and X-band MP radar is conducted as below. Ten-minute data is prepared from 1-minute data. In Figure 13, hyetographs of basin averaged 10-minute rainfall of ground observation and X-band MP radar is shown for event No.1 with maximum 30-minute cumulative rainfall volume and No.4 with large total rainfall volume, out of No.1 to No.5. Compare to 1-minute data shown in Figure 10, the two hyetographs have higher similarity in 10-minute rainfall.

Correlation coefficients between X-band MP radar and ground observation rainfall of basin averaged 10-minute rainfall is shown in Figure 14 with the same index for 1-minute rainfall. The figure shows the correlation coefficients of basin averaged 10-minute rainfall are higher than that of 1-minute for all events. It is considered that detailed variation seen in 1-minute hyetograph (Fig. 10) is smoothed thus become indistinctive in 10-minute data.
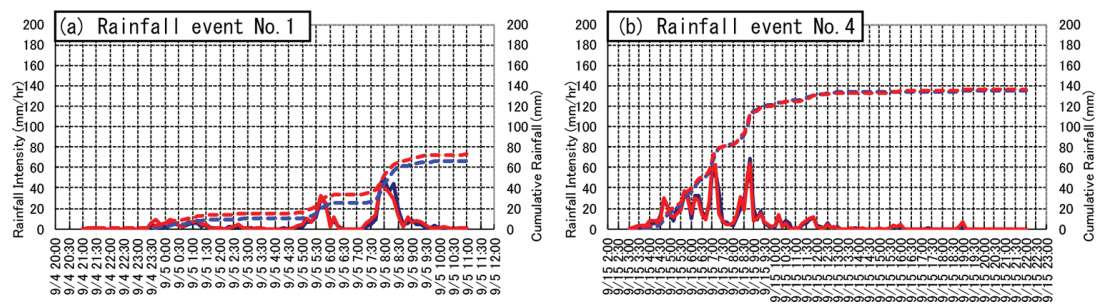

Figure 13: Comparison of ground observation and X-band MP radar for basin averaged 10-minute rainfall. (a) Rainfall event No.1; (b) Rainfall event No.4. 


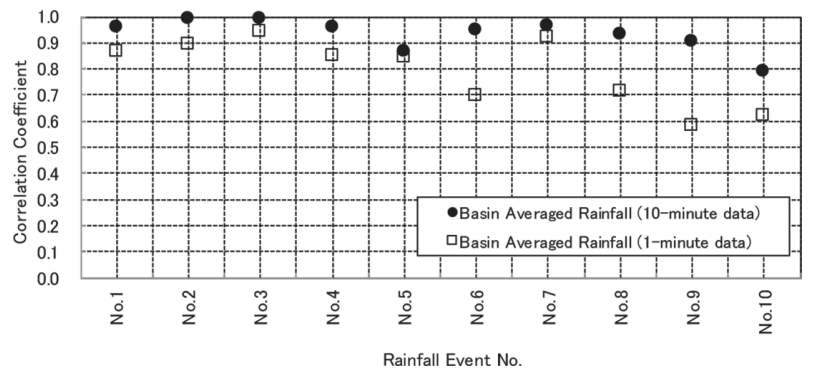

Figure 14: Correlation coefficient between ground observation and radar.

4.3 The difference between 1-minute rainfall and 10-minute rainfall in X-band MP radar data

Characteristics of 1-minute data and 10-minute data of X-band MP radar data are analysed with their hyetographs below. The basin averaged rainfall for the secondary peak of 9/5 7:0010:00 in event No.1 is shown in Figure 15. Basin averaged ground observation rainfall in 1-minute shows a peak of approximately $70 \mathrm{~mm} / \mathrm{hr}$ around 7:50, where 10-minute data shows smaller peaks with smoothed data for both ground observation and X-band MP radar.

For rainfall event No.5 with relatively large time gap between X-band MP radar data and ground observation, the basin averaged rainfall is shown in Figure 16. Rainfall event No.5 has a hyetograph with single peak in a short period. In both X-band MP radar and ground

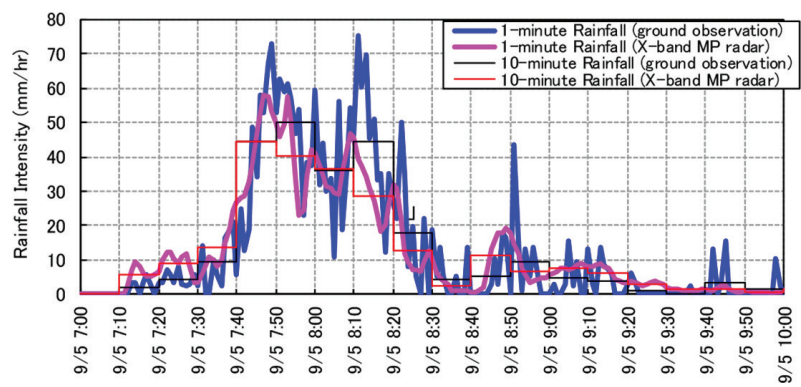

Figure 15: Comparison of basin averaged rainfall for the second half of event No.1.

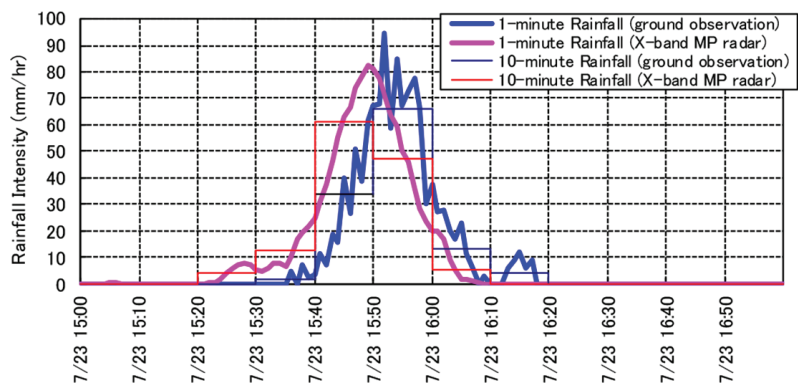

Figure 16: Comparison of basin averaged rainfall for event No.5. 
observation, the peak values of basin averaged 10-minute rainfall is approximately $30 \%$ smaller than that of 1-minute, which results in the loss of the sharpness of hyetograph. Furthermore, 2-3 minutes phase gap between peaks of 1-minute X-band MP radar and ground observation appears as 10 minutes of gap in 10-minute data. As rainfall event No.5 is induced by instability of atmospheric condition, it occurs in a remarkably short period whose duration from the start to the end is approximately 30 minutes. In small urban watersheds, flood damage induced by heavy rainfall in a short period and subsequent inner inundation is increasing. Thus, it is critical to obtain detailed hyetographs with high resolution. By using 1-minute $\mathrm{X}$-band MP radar rainfall, it is considered possible to estimate more precise peak intensity and peak occurrence time of rainfalls compare to 10-minute data.

\section{CONCLUSION}

In this study, precision evaluation of X-band MP radar rainfall is conducted utilizing densely deployed 1-minute ground observation data with the target area of the upper Kanda River basin in Tokyo. It is confirmed that 1-minute data of X-band MP radar has expected preciseness, which expresses both spatial and temporal distribution with required accuracy in small urban watersheds. Furthermore, unlike 10-minute data, it is possible to obtain detailed rainfall characteristics such as precise peak intensity and its occurring timing, by utilizing 1-minute X-band MP radar rainfall. Further studies are required to utilize detailed rainfall data of X-band MP radar for runoff, river water level, inundation, and inner water analysis. At the same time, it is expected to make clear the required spatial and temporal resolution of rainfall for target basins or rivers by analysing those distribution's impacts on the basins. To that end, further validation with ground observation data in even more detailed resolution will be required.

\section{REFERENCES}

[1] Amaguchi, H., Kawamura, A. \& Takasaki, T., Physically based distributed flood runoff model for an urban catchment using polygon feature GIS data. Doboku Gakkai Ronbunshuи B, 63(3), pp. 206-223, 2007. https://doi.org/10.2208/jscejb.63.206

[2] Takasaki, T., Kawamura, A., Amaguchi, H. \& Araki, K., New storage function model considering urban runoff process. Doboku Gakkai Ronbunshuu B, 65(3), pp. 217-230, 2009.

https://doi.org/10.2208/jscejb.65.217

[3] Tsuchiya, S., Kawasaki, M. \& Godo, H., Improvement of the radar rainfall accuracy of XRAIN by modifying of rainfall attenuation correction and compositing radar rainfall. Journal of Japan Society of Civil Engineers, Series B1 (Hydraulic Engineering), 71(4), pp. I_457-I_462, 2015.

https://doi.org/10.2208/jscejhe.71.i_457

[4] Godo, H., Naito, M. \& Tsuchiya, S., Improvement of the observation accuracy of Xband dual polarimetric radar by expansion of the condition to use KDP-R relationship. Journal of Japan Society of Civil Engineers, Series B1 (Hydraulic Engineering), 70(4), pp. I_505-I_510,2014. https://doi.org/10.2208/jscejhe.70.i_505 
[5] Tsuchiya, S., Kawasaki, M., Fukami, K., Nemoto, S., Naito, M. \& Godo, H., Trends of progress and application of radar rainfall information for the advancement of rainfall and flood forecasting technology. Journal on River Engineering, 20, pp. 343-348, 2014. https://doi.org/10.2208/prohe.50.343

[6] Hayashi, Y., Tebakari, T. \& Yamasaki, K., Accuracy of quantitative precipitation estimation by X-band multi-parameter radar using rain-gauge data over Hokuriku region. Journal of Japan Society of Hydrology and Water Resources, 27(2), pp. 67-76, 2014. https://doi.org/10.3178/jjshwr.27.67

[7] Sho, K., Taniguchi, K. \& Tominaga, A., Characteristics of rainfall areas of heavy rainfalls in Nagoya seen in 10-minute and XRAIN precipitation data. Journal of Japan Society of Civil Engineers, Series B1 (Hydraulic Engineering), 70(4), pp. I_487-I_492, 2014.

https://doi.org/10.2208/jscejhe.70.i_487

[8] Hayashi, Y., Tebakari, T., Nagashima, K. \& Yamasaki, K., Temporal-spatial distribution characteristics of quantitative precipitation estimation accuracy using X-band multiparameter radar over the Hokuriku region. Journal of Japan Society of Hydrology and Water Resources, 28(5), pp. 221-232, 2015.

https://doi.org/10.3178/jjshwr.28.221

[9] Harada, M. \& Hazumi, T., Stochastic evaluation of rainfall distribution of local heavy storms based on X-band MP radar information. Journal of Japan Society of Civil Engineers, Series B1 (Hydraulic Engineering),70(4), pp. I_511-I_516, 2014. https://doi.org/10.2208/jscejhe.70.i_511 